\title{
Association of von Recklinghausen's neurofibromatosis with adult polycystic disease of kidneys and liver
}

\author{
SubHash C. VARMA \\ M.D. \\ S. P. KAUSHIK \\ M.S.
}

K. K. TALWAR
M.D.

B. K. SHARMA

M.D.

\begin{abstract}
Departments of Internal Medicine \& Surgery, Postgraduate Institute of Medical Education and Research, Chandigarh 160012, India
\end{abstract}

\begin{abstract}
Summary
A case of von Recklinghausen's neurofibromatosis with adult polycystic disease of the kidneys and liver (APDK) is reported. Although neurofibromatosis and APDK have been reported in association with many hereditary disorders, their association together has rarely been described.

\section{Introduction}

Von Recklinghausen's neurofibromatosis and adult polycystic disease of the kidneys (APDK) are both heredofamilial disorders (Preiser and Davenport, 1918; Dalgaard, 1971) although sporadic cases also occur (Wander and Dsgupta, 1977; Hatfield and Pfister, 1972). Both the conditions are known to occur in association with a number of other hereditary disorders (Dalgaard, 1971; Koch, 1977). However, their occurrence together is a rarity (Siegelman, Javed and Hecht, 1971).
\end{abstract}

\section{Case report}

A 40-year-old married female was admitted to the Nehru hospital of Postgraduate Institute of Medical Education and Research, Chandigarh, India, with a history of generalized multiple nodular swelling for 16 years. One such swelling had been excised from the left wrist 10 years previously. Three years before admission she became aware of a soft, painless swelling behind the right ear. She noted a slowly progressive mass in the left hypochondrium and mild epigastric discomfort. There was no family history of hypertension, neurofibromatosis, APDK or renal failure. Her 5 pregnancies had been uneventful. Examination revealed a lumbar scoliosis and a blood pressure of $130 / 88 \mathrm{mmHg}$. There were multiple cutaneous swellings varying from $0.5 \mathrm{~cm}$ to $4.0 \mathrm{~cm}$ in diameter, distributed mainly over the trunk (Fig. 1)

Reprint requests to Dr B. K. Sharma.

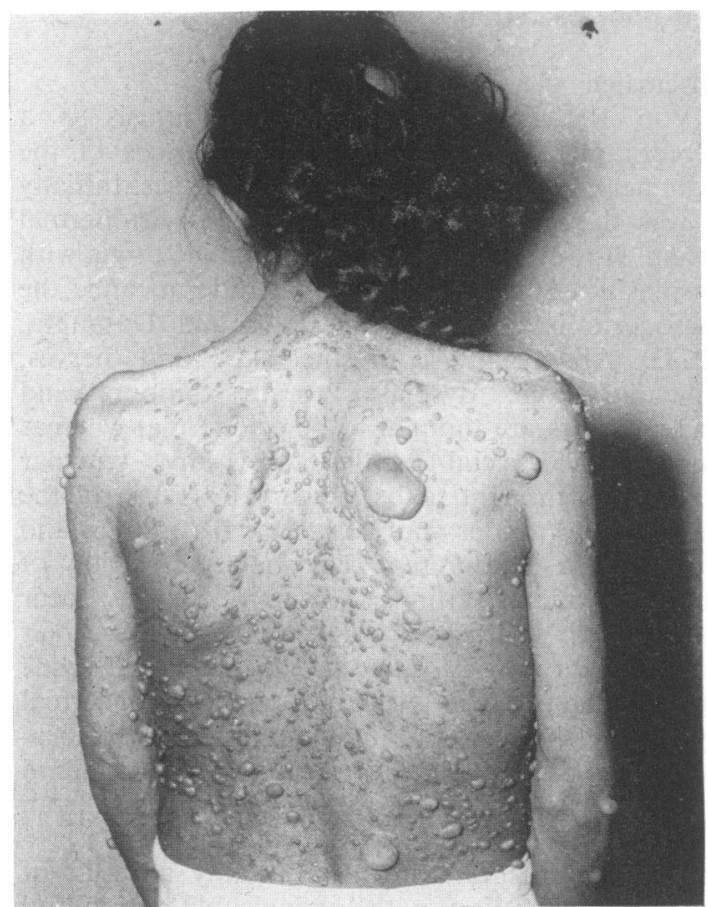

Fig. 1. Photograph showing multiple cutaneous neurofibromas.

and the face and many café-au-lait spots. There was a plexiform neurofibroma over the left wrist extending to the left little finger. There was a pulsatile, $2.5 \mathrm{~cm} \times 1 \mathrm{~cm}$ swelling with a continuous bruit in the right postauricular region. The liver was palpable $14 \mathrm{~cm}$ below the right costal margin and there was a bimanually palpable mass in the left lumbar region. The optic fundi were normal. 
Investigations revealed haemoglobin of $10 \cdot 2 \mathrm{~g} / \mathrm{dl}$. Blood urea was $5.9 \mathrm{mmol} / \mathrm{l}$, serum creatinine $114.9 \mu \mathrm{mol} / \mathrm{l}$. Urine examination did not reveal proteinuria or microscopic haematuria. Radiology showed angulation of the second, third and fourth ribs on the right side, wedging of the L5 vertebra and an osteolytic defect in the occipital region of the skull which was the site of a vascular malformation. There was resorption of the distal end of the left ulna, pisiform and triquetral bones with a soft tissue swelling and the right humerus was broader with increased thickness of the cortex.

Because of the suspicion of a retroperitoneal tumour, an exploratory laparotomy was done and the liver and kidneys were found to be enlarged and polycystic. Liver biopsy confirmed the diagnosis of a polycystic liver.

Postoperatively an intravenous urogram was done which showed large kidneys with stretched calyces and poor excretion.

\section{Discussion}

Von Recklinghausen's neurofibromatosis is a heredofamilial disorder with abnormalities of the skin, nervous system, bones and soft tissues. Initially it was thought to be purely of neuro-ectodermal origin. However, now a dual embryologic origin with dysplasia of both the neuro-ectoderm and the mesoderm is postulated (Wander and Dasgupta, 1977). Abnormalities of the skin and nerves, sphenoid bone dysplasia, brain tumours and meningiomas are thought to be ectodermal whereas non-cranial skeletal manifestations and vascular lesions are thought to be primary dysplasia of the mesoderm (Wander and Dasgupta, 1977; Hunt and Pugh, 1961). The present case showed a variety of cutaneous manifestations. The bone changes occur usually with soft tissue overgrowth. However, their development may be independent of the soft tissue changes and probably occur as a part of mesodermal dysplasia (Wander and Dasgupta, 1977). Resorption of the distal end of the ulna and carpal bones in this case was probably as a result of pressure from the adjacent plexiform neurofibroma.

Vascular manifestations are usually a result of intimal proliferation, with luminal obliteration and perivascular nodule formation around the arterioles (Reubi, 1945). Similar disease may involve the aorta and its branches which may have poststenotic aneurysmal dilatation (Itzchale et al., 1974). Although involvement of intracranial vessels has not been reported, it is a possible explanation for the vascular swelling in this patient.

APDK is also inherited as an autosomal dominant disorder. In about one-third of the cases, cystic disease of the liver is present, which was so in this $c$. case. Both APDK and neurofibromatosis have been $\Rightarrow$ described independently in association with a number of hereditary disorders. However, the authors could find only one such instance when $\frac{\bar{O}}{\overline{0}}$ these disorders occurred together (Siegelman et al., $\frac{\bar{\sigma}}{\widetilde{\alpha}}$ 1979). A patient with juvenile polycystic kidneys with $\varrho$ congenital hepatic fibrosis, and neurofibromatosis has also been reported (Carty and Jones, 1978).

Occurrence of the 2 disorders together cannot be $\stackrel{\circ}{-}$ explained on the basis of linked gene loci because of $\vec{\omega}$ the rarity of the association in spite of the relatively $\stackrel{\circ}{\circ}$ common incidence of both disorders in the generalo population. Since the kidneys develop from meso- 3 . dermal tissue and there is mesodermal dysplasia in $\bigcup_{\infty}$ neurofibromatosis, a common developmental basis $\sigma$ for the association may be postulated. Dysplastic $\overparen{ }$ kidneys may have multiple cysts (Gur et al., 1975) $\overrightarrow{-}$ and are sometimes associated with other hereditary $\vec{V}$ disorders (Bernstein, 1971) but this is not relevant to $\frac{\text { 의 }}{2}$ the present case. It would therefore appear that the association may merely be a matter of chance.

\section{References}

BERNSTEIN, J. (1971) Heritable cystic disorders of the kidney융 $\overrightarrow{0}$ the mythology of polycystic disease. Pediatric Clinics of North America, 18, 435.

CARTY, J.E. \& JONES, C.T.A. (1978) Juvenile hepatic fibr予 polycystic disease and other abnormalities. Postgraduate Medical Journal, 54, 353.

DalgaARd, O.Z. (1971) Polycystic disease of the kidneys. In: Diseases of the Kidney, 2nd edn (Ed by Strauss M. B. \& 음 Welt E. G.), p. 1223. Little, Brown and Co., Boston.

Gur, A., Seigel, N.J., Davis, C.A., Kashgarian, M. \& $\stackrel{2}{\rightrightarrows}$ HAySLETT, J.P. (1975) Clinical aspects of bilateral renal $\overline{\mathrm{O}}$ dysplasia in children. Nephron, $15,50$.

Hatfield, P.M. \& Pfister, R.C. (1972) Adult polycystic disease of the kidneys. Journal of the American Medical Association, 222, 1527.

Hunt, J.C. \& Pugh, D.C. (1961) Skeletal lesions in neurofibromatosis. Radiology, 76, 1.

Itzchale, Y., Katnelson, D., Boichis, R., Jonas, R. \& Deutsch, V. (1974) Angiographic features of arterial 3 lesions in neuofibromatosis. American Journal of Roentgenology, Radium Therapy and Nuclear Medicine, 122, 643. 윽

Косн, G. (1977) Genetic aspects of neurofibromatosis. In: Handbook of Clinical Neurology, Vol. 14, p. 492. North 을 Holland Publishing Company, Amsterdam.

Preiser, S.A. \& DAVenPort, C.B. (1918) Multiple neuro- $\frac{7}{O}$ fibromatosis (Von Recklinghausen's disease) and its inheritance. American Journal of the Medical Sciences, $\bar{N}$ $156,507$.

ReUBI, F. (1945) Neurofibromatoses et lésions vasculaires. Shweizerische medizinische Wochenschrift, 75, 463.

Siegelman, S.S., JaVed, R. \& BeChT, H. (1971) Neurofibromatosis, polycystic kidneys and hypernephroma. New York State Journal of Medicine, 71, 2431.

WANDER, J.V. \& DAS GuPTA, T.K. (1977) Neurofibromatosis. Current Problems in Surgery, 15, 5. 